\title{
Entre a macrorreferencialização da avaliação do desempenho docente e a burocracia periférica
}

\author{
Henrique Ramalho \\ Escola Superior de Educação - Instituto Politécnico de Viseu - CI\&DETS, Portugal
}

\begin{abstract}
Resumo
Inscrito no paradigma compreensivo weberiano, este ensaio concretiza uma proposta de interpretação e compreensão das diversas relações estabelecidas entre a macrorreferencialização da avaliação do desempenho docente e os respetivos movimentos (re)produtores operados ao nível da burocracia periférica. Concludentemente, destacamos, por um lado, a concretização de um esquema de engajamento organizacional de onde sobressaem a lideranças “emergentes”, sedeadas num novo locus de autoridade e poder legais. Por outro, alertamos para o efeito da subordinação hierárquica de matriz gerencialista, enquanto tecnologia de regulação periférica da ação dos docentes, a par de um reforço do efeito regulamentar exercido a partir do centro.

Palavras-chave: avaliação de desempenho docente; macrorreferencialização; burocracia periférica.
\end{abstract}

\section{Nota introdutória: metodologia, enquadramento e objetivos}

Enquadrado num estudo empírico de maiores dimensões a que demos a designação parcial de “Avaliação do Desempenho Docente: Dilemas e (Im)Possibilidades de uma Referencialização Multifocalizada” (Ramalho, 2012, p. 461), este texto configura uma proposta de análise e interpretação das interações institucionais e sócio-organizacionais intercedidas pelas políticas e práticas de avaliação do desempenho docente na escola básica portuguesa. Congruentemente, suscitamos um foco de análise que tece considerações sobre as tensões e oportunidades ocorridas entre a prescrição central da avaliação e a experiência de “avaliar” e "ser avaliado" na periferia.

Em linha com o quadro epistemológico sedeado nas ideias-base da sociologia compreensiva sociológica (cf. Weber, 1983; 1997), optou-se por uma orientação metodológica que abarca algumas características de um “estudo de caso” (cf. Bogdan \& Biklen, 1994, p. 89). Esta aproximação à metodologia do estudo de caso foi caracterizada pelo seu caráter qualitativo ou "naturalístico", enveredando pela observação de um contexto escolar específico.

Ao inscrever o nosso ensaio metodológico e o consequente trabalho empírico na perspetiva do "estudo de caso de observação” (Bogdan \& Biklen, 1994, p. 90) operado no contexto de um agrupamento de escolas de configuração vertical, não pretendemos demarcá-lo com o critério da representatividade estatística. Na presente discussão, o trabalho metodológico envolveu, entre outras tarefas, a construção e operacionalização dos seguintes instrumentos de recolha de dados: i) inquérito por questionário aplicado a 156 docentes, com uma taxa de retorno de $87 \%$; ii) inquérito por entrevista, realizado aos seguintes informantes-chave: Coordenador de Estabelecimento/relator do $1 .^{\circ}$ ciclo, Diretor/Presidente do Conselho Pedagógico/ Coordenador da Comissão de Coordenação da Avaliação do Desempenho, Relatora do $3 .^{\circ}$ ciclo, Coordenadora do Departamento do Pré-escolar, Coordenadora do Departamento do $1 .^{\circ}$ ciclo, Coordenadora do Departamento das Expressões, Coordenadora de Departamento de Línguas, Relatora do Pré-escolar, Coordenador do Departamento de Ciências Sociais e Humanas, Relator do 2. ${ }^{\circ}$ ciclo; iii) análise documental a 56 documentos com origem na administração central e no agrupamento de escolas estudado.

Em termos procedimentais, recorremos a várias técnicas de observação, designadamente, a entrevistas em profundidade com atores perspetivados como informantes chave do agrupamento observado, aos documentos oficiais e oficiosos escritos existentes, a testemunhos ou documentos pessoais e, a título de complementaridade, ao inquérito por questionário, vincando-se, assim, um esforço intencional para proceder ao exercício da "triangulação" de dados (Ludke \& André, 1986, p. 52) a partir de diversas fontes de evidência (Yin, 1994).

Interessados em manter a atitude sociológica compreensiva e interpretativa weberiana, ainda que tal procedimento se mantenha implícito neste texto, recorremos à análise de conteúdo, implicando um processo de inventariação e sistematização das principais dimensões e categorias de análise, para passar à construção do texto de interpretação dos dados (cf. Bardin, 1995).

Congruentemente, concretizamos uma análise através da qual se procura revelar representações, sentidos e significados dos atores, partindo de diversos elementos constitutivos dos discursos observados (Quivy \& Campenhoudt, 1998, p. 228), procedendo, ao mesmo tempo, a um exercício de síntese que concretiza o manancial de dados disponíveis num discurso coerente face às nossas principais dimensões e categorias de análise.

Porquanto, o presente texto configura parte de um trabalho "sinergético" (cf. Estêvão, 1998, p. 356) utilizado como suporte a um exercício de reteorização, precisamente com a função de analisar, (re)interpretar a realidade observada (cf., a propósito, Ezpeleta \& Rockwell, 1989). 


\section{Apresentação de alguns resultados}

Pelos dados disponíveis, verificámos que o exercício de adaptação das referências nacionais da avaliação do desempenho docente às dinâmicas internas do agrupamento surgem como uma reprodução quase mimética dos domínios e itens/indicadores definidos pelo Ministério da Educação. A confirmar aquela reprodução da prescrição central de domínios e indicadores de avaliação, verifica-se, pela análise do gráfico 1 que existe um elevado grau de concordância sobre o facto dos domínios, critérios e indicadores da avaliação do desempenho decorrerem, fundamentalmente, da prescrição central:

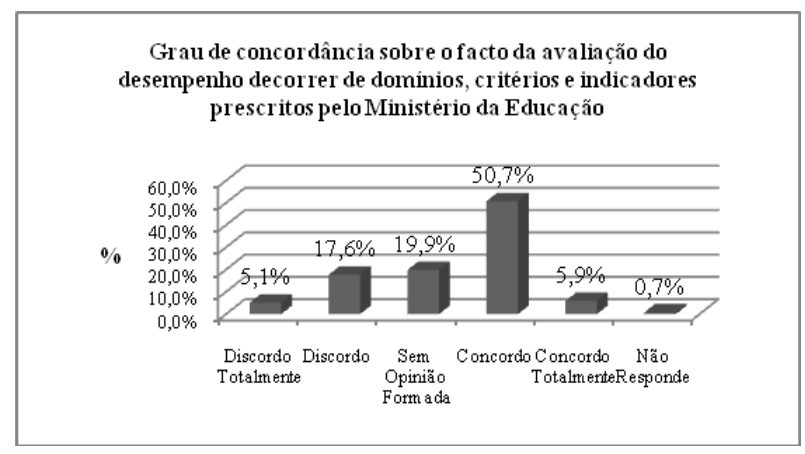

Figura 1. Perceção sobre a macrorreferencialização

Por outro lado, a avaliação do desempenho docente emerge, na perspetiva dos docentes entrevistados, como uma tecnologia de prestação de contas que serve os interesses do Ministério da Educação, pelo que

[...] estamos a prestar contas aos senhores de lá do governo que querem fazer de conta lá para a União Europeia... que temos gente que está... que tem médias... que atingiram X \% de qualificação... e a outra parte outra vez da economia. O que querem é ter alunos com a qualificação... economizar, mas não sei se os meninos que vão ter o $12^{\circ}$ serão capazes (E3),

tratando-se de um exercício de prestação de contas que, para a maioria dos docentes inquiridos (61,8\%), está, claramente, focalizado na administração central:

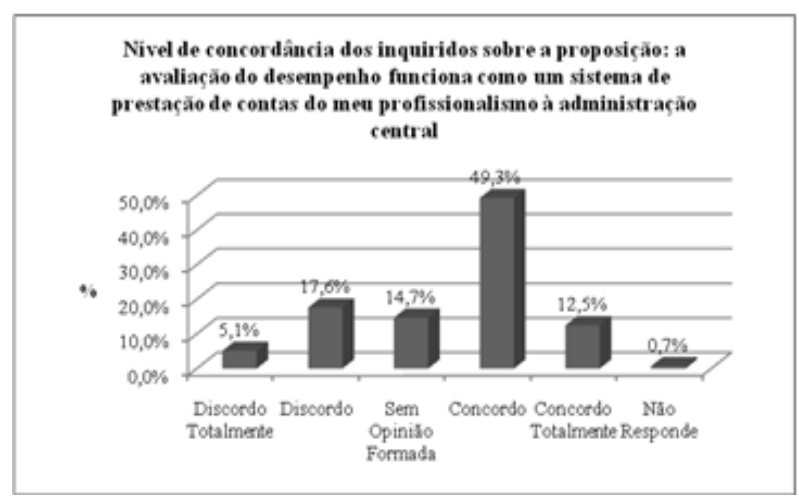

Figura 2. Um dos efeitos da macrorreferencialização

Consequentemente, registaram-se efeitos importantes ao nível do engajamento dos atores com funções de gestão e execução da avaliação. Para uma grande parte dos inquiridos significa que, por exemplo, a figura do relator/avaliador emerge como alguém que detém mais autoridade formal e, consequentemente, mais poder, decorrente da capacidade para os usar sobre os avaliados, definindo-se relações hierárquicas perfeitamente decorrentes dessa diferenciação de posse de autoridade formal e da capacidade do uso do poder que lhe está inerente.

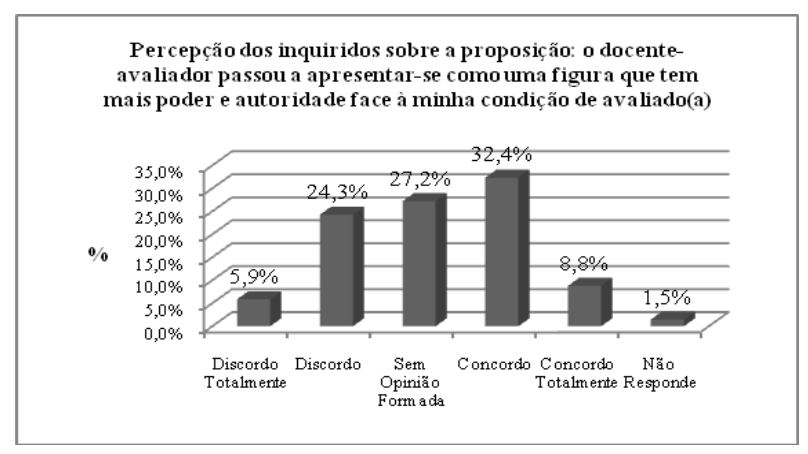

Figura 3. A avaliação como fonte de poder e autoridade

Congruentemente, faz-se notar efeito da subordinação hierárquica dos avaliados, em que parece ganhar plausibilidade que se fale da emergência dos novos supervisores a quem são delegados determinados poderes e mandatos de autoridade.

\section{Discussão 1: o efeito centro burocrático das referências macrodiscursivas}

A prerrogativa enunciada pela linha do eixo burocrático (Ramalho, 2012) alusiva à macroestrutura do sistema educativo concretiza uma perceção da referencialização baseada no discurso oficial do significado do desempenho docente e consequente avaliação, em que as estruturas, os normativos, as práticas e os comportamentos surgem, na perspetiva da face oficial do sistema educativo, estruturados por via da normalização burocrática central (cf. Decreto-Lei ${ }^{\circ}$ 15/2007, de 19 de janeiro).

Daqui sobressai o caráter isomórfico do referencial da avaliação na sua versão oficial e a perspetivação do desempenho docente como objeto de avaliação macrorreferencializado, através de referências centrais pré-estabelecidas (cf. Despacho no 16034/2010, de 22 de outubro; Decreto Regulamentar n. ${ }^{\circ}$ 26/2012, de 21 de fevereiro). Com efeito, os pressupostos que decorrem do eixo burocrático da administração central são verificáveis por via de um exercício de prescrição capaz de decidir sobre a habilitação, e normalizar o acesso a um determinado estatuto de realização e ação profissional dos docentes.

O efeito de normalização do acesso a um determinado estatuto de realização e ação profissional dos docentes proporciona uma lógica de distribuição e diferenciação legais das funções docentes, em função da hierarquização administrativa da carreira e da verticalização das relações socioprofissionais. Verificámos que, alinhando a sua ação com esses pressupostos, o Ministério da Educação concretiza uma clara diferenciação de funções entre docentes pela via da "[...] senioridade na profissão, ao propiciar-se a docentes situados nos últimos escalões da carreira a sua 
dedicação a diversas funções especializadas” (cf. n. ${ }^{\circ}$ 6, do artigo 35. ${ }^{\circ}$, do Decreto Lei n. $^{\circ}$ 75/2010, de 23 de junho), percebendo-se que o processo de diferenciação de funções, seguindo a via da hierarquização do tipo vertical, alinhou-se com uma orientação de inspiração fayolista (cf. Fayol, 1984; Lody, 1971) do legislador garantir o primado da avaliação bem administrada.

Congruentemente, o arranjo macroinstitucional que desocultámos no manancial de dados que recolhemos sugere uma arquitetura do sistema de avaliação baseada numa estrutura orgânica de gestão e execução periféricas, precisamente tendo em vista a coordenação de todo o processo, o acompanhamento e supervisão do desempenho dos avaliados, o acompanhamento e supervisão do desempenho dos avaliadores e a execução e tomada de decisão final sobre o processo avaliativo, a que se acrescenta uma quase sacralizada crença na superioridade técnica dos principais intervenientes no processo. Além disso, a função de avaliar, estando distribuída por funções mais específicas associadas a cada um dos intervenientes anteriormente referidos, surge amplamente prescritiva, sendo tratada pelo legislador com uma afirmação, por um lado, de responsabilidade inviolável e, por outro, de perda de estatuto por parte dos protagonistas como consequência da sua não aplicação (cf. Decreto Regulamentar n. ${ }^{\circ}$ 2/2010, de 23 de junho), emergindo, assim, como algo que decorre da efetividade da pressão técnicoburocrática (Bernardes, 1990).

A propósito, o legislador prescreve determinadas referências de desempenho, em cuja definição o observador-avaliador e o avaliado são formalmente colocados numa situação de completa exterioridade face ao respetivo processo de definição, mantendo a interferência daqueles atores periféricos suficientemente distante da zona de influência da normalização do desempenho docente e da sua avaliação (cf. Despacho $\mathrm{n}^{\circ}$ 16034/2010, de 22 de outubro; Decreto Regulamentar n. ${ }^{0}$ 26/2012, de 21 de fevereiro). Assim, a avaliação do desempenho docente insere-se no quadro da avaliação reguladora, arrolada na deriva autoritarista (Hadji, 1994) do Estado avaliador, encerrando o recurso a um determinado quadro de referências, referenciais e referentes com origem numa ditadura administrativa, que o Estado utiliza para afirmar o seu poder como possibilidade de se fazer obedecer em função de um determinado mandato prescrito por normas legais, alinhando-se com uma dinâmica de poder que tende a conservar, reproduzir e perpetuar uma certa ordem das coisas (Hadji, 1994, p. 114), em especial, a estratificação social e profissional do corpo docente que lhe é mais favorável.

Daqui sobressaem aspetos típicos da (re)centralização burocrática das políticas educativas, instrumentalizando-se a avaliação como mecanismo de recentralização administrativa da educação, e concretizando-se a ideia de referencial central como algo que pré-existe à ação periférica (cf. $\mathrm{n}^{\circ} 4$ do anexo ao Despacho $n^{\circ} 16034 / 2010$, de 22 de outubro), pelo que, em discurso oficial, falar de processos de referencialização que envolvam a participação dos atores da periferia fará pouco ou nenhum sentido, estando o discurso oficial apenas interessado no engajamento burocrático e normativo - tipicamente reprodutor - o presidente do conselho geral; o diretor; a secção de avaliação de desempenho docente do conselho pedagógico e os avaliadores externos e internos (cf. Decreto Regulamentar n. ${ }^{\circ}$ 26/2012, de 21 de fevereiro). Ao mesmo tempo, as lógicas de liderança que atravessam aquele quadro de gestão e execução das políticas e práticas de avaliação do desempenho docente tendem a tipificar-se segundo a configuração do "líder treinado" em função das "melhores maneiras" de atuar (Costa, 2000, p. 19), burocraticamente definidas, em que os líderes, estando dispersos por uma hierarquia de avaliação verticalizada e hermética, protagonizam esquemas de liderança gestionária da avaliação.

Assim, não será de estranhar que associemos à avaliação do desempenho a metáfora do controlo à distância (cf. Estêvão, 1995) da ação docente e do próprio funcionamento do agrupamento e escolas agrupadas, seja do ponto de vista organizativo e administrativo, seja do ponto de vista da gestão curricular e pedagógica. Congruentemente, termos como centralização, descentralização, autonomia, participação e colegialidade, tendem a ser inscritos num discurso instrumental em prol da (re)centralização, da (re)burocratização e da despolitização dos contextos e processos de tomada de decisão educativa, com especial incidência no quadro da referencialização da avaliação de professores e educadores, de onde a imagem do Estado regulador sai francamente reforçada. Efetivamente, as políticas e, mais concretamente, as práticas de avaliação do desempenho docente são claramente inscritas na conceção gestionária da educação e do próprio corpo docente, alinhando-se com o pressuposto da "gestão que atua na periferia (na escola) como um mecanismo que oculta um controlo à distância, mimetizado num efeito de "retorno do poder e da reconstrução do paradigma da centralização" (Lima, 1998).

\section{Discussão 2: as lógicas do engajamento dos atores escolares operadas a partir da burocracia periférica}

A análise dos nossos dados empíricos remeteu-nos para a esfera do eixo da burocracia periférica, com os designados movimentos integradores da avaliação, vislumbrados a partir de uma socialização socioprofissional conforme à norma central e das consequentes tendências para a reprodução do padrão avaliativo central. Tais movimentos denunciam uma instrumentalização da ação dos docentes na perspetiva da gestão normalizada segundo uma lógica de agência de gestão do Ministério da Educação, em que a avaliação do desempenho concretiza um sentido reprodutor e institucionalizador dos pressupostos educativos centrais do tipo descendente ou top-down (Bolívar, 2000).

As ponderações e as racionalidades limitadas (cf. Simon, 1983; March \& Simon, 1974) com sentidos múltiplos que os docentes vão construindo e desenvolvendo acerca do sistema de avaliação e da sua própria condição de avaliados são equacionadas em 
função de perdas e ganhos de carreira (de uns sobre os outros e face ao próprio sistema), decorrentes de uma maior ou menor adesão ou, dito de outra forma, de um maior ou menor comprometimento com o sistema.

Além disso, a nossa análise submete-nos à discussão dos pressupostos inerentes ao eixo da burocracia periférica, sugerindo um engajamento organizacional de onde sobressaem os denominados atores “emergentes”, designadamente a figura, num primeiro momento, do relator e, mais tarde, do avaliador (interno e externo), sedeada num novo locus de autoridade e poder legais de onde sobrevém, também, o efeito da subordinação hierárquica dos avaliados, em que parece ganhar plausibilidade que se fale da emergência dos novos supervisores a quem são delegados determinados poderes e mandatos de autoridade, sem que seja plausível falar na delegação de liderança (cf. Decreto Regulamentar $n^{\circ}$ 2/2010, de 23 de junho; Decreto Regulamentar n. ${ }^{\circ}$ 26/2012, de 21 de fevereiro).

Portanto, da "nova” estrutura hierárquica associada à implementação do sistema de avaliação, novos “funcionários burocráticos” (Weber, 1983), novas relações e funções sócio-organizacionais, profissionais e pessoais emergem no agrupamento e nas escolas que dele fazem parte, de onde se destaca a instrumentalização dos atores da periferia como "recolectores" da “informação de base” (Lima, 2011, p. 37). Congruentemente, no novo quadro regulamentar da avaliação do desempenho docente, as relações de poder e de autoridade formais decorrentes da institucionalização desses novos funcionários burocráticos tendem a capacitar determinados atores (avaliadores) em detrimento de outros (avaliados) para o uso de um grau de poder e autoridade formais acrescidos, quando comparado com o passado recente. Essa capacidade do uso de poder, destacando o poder advindo da esfera restrita da avaliação do desempenho, estabelece a relação entre os docentes a quem é legalmente reconhecida a capacidade para gerir/coordenar, supervisionar e avaliar - duplo efeito de mando e dominação - e os docentes que têm de se submeter à execução da avaliação e às suas consequências - duplo efeito de obediência e sujeição (Srour, 1998, p. 135). Consequentemente, gera-se uma pressão sobre o cumprimento de resultados centralmente pré-formatados, instalando, ao mesmo tempo, um controlo de cunho tecnocrático que propicia a desvalorização da relevância social e política da ação participativa dos docentes (Misuraca, Cerruti \& Rocha, 2013).

Consequentemente, assistimos a uma (re)configuração hierárquica - saída da arquitetura do sistema de avaliação do desempenho - que é realçada pelo facto de dar origem a "beneficiários" mais diretos e mais interessados na sua institucionalização, criando algum dissentimento entre a contestação de alguns que se sentem ameaçados, e a aceitação de outros, por acreditarem que a adoção das regras instituídas simbolizam uma vantagem da qual podem fazer um uso estratégico no quadro da dinâmica organizacional.

Nestes termos, ao serem influenciados pela dinâmica administrativa, aqueles "beneficiários" mais diretos tendem a adotar estratégias pessoais e grupais no sentido de proteger e promover os seus próprios interesses, sendo que procuram consolidar um padrão burocrático periférico que lhes permita estabilizar o sistema e, por outro lado, evitar a emergência e implementação de posicionamentos mais contestatários que ameacem os seus próprios interesses (cf. Beetham, 1987), e situações estáveis que construíram até ao momento e às quais acomodaram a sua ação organizacional. Congruentemente, a estratégia da responsabilização - accountability (Afonso, 2009) permite aos principais intervenientes na avaliação reforçar e legitimar o seu poder para o exercício do qual estão administrativamente mandatados.

Também por isso, pudemos observar que no complexo jogo da avaliação, especialmente no que concerne à sua gestão e institucionalização periféricas, o engajamento burocrático e normativo dos gestoresavaliadores ocorre, desde a origem do sistema de avaliação, com efeito prescritivo a partir do referencial central, decorrendo daí um grau elevado de comprometimento desses atores com o trabalho de organizar o tipo de resposta que o discurso oficial, de alguma forma, antecipa (cf. n. ${ }^{\circ} 4$, do art. $^{\circ} 5 .^{\circ}$ do Decreto-Lei n. ${ }^{\circ}$ 75/2010, de 23 de junho).

Inserida, assim, no paradigma da "dominação legal da administração burocrática” (Weber, 1993, p. 173) a avaliação do desempenho constitui um corpus de direito legal racionalmente instituído, incorporando um conjunto de regras intencionalmente prescritas no quadro da “dominação legal” e da consequente “expectativa programática” (Mayntz, 1977, p. 106), a que corresponde, também, uma forma específica da distribuição do poder na organização escolar, claramente condicionada por uma "superimposição normativa” e alienada à "execução em conformidade" da ação periférica (Lima, 1998, p. 171-174).

As funções de recolha e análise de informação avaliativa decorrem, ainda, da atuação e do próprio engajamento prescrito dos atores burocraticamente mandatados para o exercício de um papel relevante no jogo da avaliação, reforçando-se, assim, a sua posição no locus burocrático e na "nova” estrutura hierárquica da periferia decorrente das políticas e práticas de avaliação do desempenho (cf. $n^{\circ} 6$, do art. $^{\circ} 35^{\circ}$, do Decreto-Lei $n^{\circ} 75 / 2010$, de 23 de junho; Decreto Regulamentar n. ${ }^{\circ}$ 26/2012, de 21 de fevereiro), alinhando-se com a prerrogativa da extração de contas (Lima, 2011), tacitamente instrumentalizada por parte do Ministério da Educação.

\section{Conclusão}

Subjazem à institucionalização das políticas e práticas de avaliação do desempenho docente importantes transformações ao nível da "velha" hierarquia do corpo docente, observando-se uma clara tendência para a sua verticalização, muito por causa da emergência de novas relações de poder, de autoridade e de influência na escola e na sala de aula. Efetivamente, vimos que o arranjo macroinstitucional da avaliação sacraliza o arquétipo da "senioridade" como forma de promover 
uma reestruturação das relações socioprofissionais, que passam a caracterizar a hierarquia do pessoal docente, sendo esta a via fundamental que marca a tendência para a verticalização das relações hierárquicas estabelecidas entre os docentes. Concomitantemente, concretiza-se um esquema de engajamento organizacional de onde sobressaem os designados atores "emergentes", sedeados num novo locus de autoridade e poder legais de onde sobrevém, também, o efeito da subordinação hierárquica dos avaliados. Assim se sintetiza a referida verticalização da estrutura hierárquica do corpo docente.

Além disso, constata-se que predomina um quadro de referências, referentes e, portanto, um quadro referencial da avaliação do desempenho que decorre da instrumentalização da autonomia do agrupamento ou, inversamente, da falta dela.

Pela imposição normativa que "vem muito de cima", as políticas e práticas de avaliação do desempenho docente tendem a ser instrumentalizadas, adotando um perfil de "autoperpetuação" do próprio esquema burocrático que as criou, asfixiando as referências que emergem da circunstância mais espontânea das orientações meso e, sobretudo, microdiscursivas. Inversamente, as ambições autonómicas do agrupamento e dos seus atores, argumentadas pelos próprios como mecanismo que deveria ser privilegiado na operacionalização das dimensões e indicadores da avaliação do desempenho docente mais contextualizadas, mantêm-se em contracorrente com aquilo que, eles próprios, alegam ser as dimensões de avaliação afetas aos interesses do Ministério da Educação.

\section{Referências}

Afonso, A. (2009). Nem tudo o que conta em educação é mensurável ou comparável: Crítica à accountability baseada em testes estandardizados e rankings escolares. Revista Lusófona de Educação, 13, 13-29.

Bardin, L. (1995). Análise de Conteúdo. Lisboa: Edições 70.

Beetham, D. (1987). Burocracia. Lisboa: Editorial Estampa.

Bernardes, C. (1990). Sociologia Aplicada à Administração. S. Paulo: Editora Atlas, S.A.

Bogdan, R. \& Biklen, S. (1994). Investigação Qualitativa em Educação: uma introdução à teoria e aos métodos. Porto: Porto Editora.

Bolívar, A. (2000). O Lugar da Escola na Política Curricular Atual: para além da reestruturação de da descentralização. In Manuel Jacinto Sarmento (org.). Autonomia de Escola. Políticas e Práticas. Porto: Edições Asa, pp. 157-190.

Costa, J. (2000). Lideranças nas Organizações: revisitando teorias organizacionais num olhar cruzado sobre as escolas. In Jorge Adelino Costa; António Neto Mendes e Alexandre Ventura (orgs.). Liderança e Estratégia nas Organizações Escolares (pp. 15-34) Aveiro: Universidade de Aveiro.

Decreto-Lei n. ${ }^{\circ}$ 15/2007, de 19 de janeiro. Altera o estatuto da carreira docente.
Decreto-Lei n. ${ }^{\circ}$ 75/2010, de 23 de junho. Altera o estatuto da carreira docente.

Decreto Regulamentar n. ${ }^{\circ}$ 2/2010, de 23 de junho. Regulamenta os sistemas de avaliação do desempenho do pessoal docente.

Decreto Regulamentar n. ${ }^{\circ}$ 26/2012, de 21 de fevereiro. Estabelece os princípios que presidem ao estabelecimento do regime de avaliação do desempenho docente.

Despacho $n^{\circ} 16034 / 2010$, de 22 de outubro. Define os padrões de desempenho docente.

Estêvão, C. (1995). O Novo Modelo de Direção e Gestão das Escolas Portuguesas: a mitologia racionalizadora de uma forma organizacional alternativa. In Revista Portuguesa de Educação, 8 (1), 87- 98.

Ezpeleta, J. \& Rockwell, E. (1989). Notas Sobre Pesquisa Participante e Construção Teórica. In Justa Ezpeleta e Elsie Rockwell (eds.) Pesquisa Participante. S. Paulo: Editora Cortez, pp. 77-93.

Fayol, H. (1984). Administração Industrial e Geral. São Paulo: Ed. Atlas.

Hadji, C. (1994). Avaliação: regras do jogo. Porto: Porto Editora.

Lima, L. (1998). A Escola Como Organização e a Participação na Organização Escolar. Braga: Centro de Estudos em Educação e Psicologia.

Lima, L. (2011). Conceções de escola: Para uma hermenêutica organizacional. In Licínio Lima (Org.). Perspetivas de análise organizacional da escola (pp. 15-57). Vila Nova de Gaia: Fundação Manuel Leão.

Lodi, J. (1971). História da Administração. São Paulo: Biblioteca Pioneira da Administração de Negócios.

Ludke, M. \& André, M. (1986). Pesquisa em Educação: abordagens qualitativas. São Paulo: Editora Pedagógica e Universitária.

March, J. \& Simon, H. (1974). Les Organisations. Paris: Dunod.

Mayntz, R. (1977). Sociología de la Organización. Madrid: Alianza Editorial.

Misuraca, M.; Cerruti, M. \& Rocha, S. (2013). Políticas para evaluar la calidad de la educación en Argentina después de los '90. Currículo sem Fronteiras, 13(2), 269-286. Acedido em 2 de março, 2015, em http://www.curriculosemfronteiras.org/vol13iss2articl es/misuraca-cerruti-rocha.htm

Quivy, R. \& Campenhoudt, L. (1998). Manual de Investigação em Ciências Sociais. Lisboa: Gradiva.

Ramalho, H. (2012). Escola, professores e avaliação: Narrativas e racionalidades da avaliação do desempenho docente na escola básica portuguesa (Tese de doutoramento). Universidade do Minho, Braga.

Simon, H. (1983). Administration et Processus de Décision. Paris: Economica.

Srour, R. (1998). Poder, Cultura e Ética nas Organizações. Rio de Janeiro: Campus.

Tyler, R. (1949). Princípios Básicos de Currículo e Ensino. Rio de Janeiro: Editora Globo. 


\section{RAMALHO}

Weber, M. (1983). Fundamentos da Sociologia. Porto: Rés Editora.

Weber, M. (1993). Economía y Sociedad: esbozo de sociología comprensiva. México: Fondo de Cultura Económica.
Weber, M. (1997). Conceitos Sociológicos Fundamentais. Lisboa: Edições 70.

Yin, R. (1994). Aplications of Case Study Research: methods. Newbury Park: Sage Publications. 